\title{
La iluminación en alta definición de la séptima temporada de la telenovela de Televisión Española Amar en tiempos revueltos*
}

\author{
Gaspar Cerdá Juan** \\ Recibido: 2019-02-08 • Enviado a pares: 2019-02-20 \\ Aprobado por pares: 2019-015 - Aceptado: 2019-05-20 \\ https://doi.org/10.22395/angr.v18n35a7
}

\begin{abstract}
Resumen
En el presente artículo se analiza la forma en que los profesionales de la iluminación articulan las posibilidades expresivas de la luz para apoyar la producción española de la ficción televisiva seriada en alta definición; cómo distribuyen la luz para adecuarla a las necesidades narrativas de la escena y las exigencias técnicas de las cámaras de televisión. El caso de estudio escogido es la séptima temporada de Amar en tiempos revueltos, producida por Diagonal TV para Televisión Española, ya que es una de las series más laureadas de Televisión Española, y supera en número de capítulos al resto de telenovelas de emisión nacional. El déficit de fundamentación teórica llevó a realizar entrevistas en profundidad con los directores de fotografía e iluminadores en estas producciones televisivas. Para el tratamiento de los datos obtenidos mediante la técnica dialógica y el visionado directo de los episodios de la ficción, se empleó la metodología cualitativa del análisis de contenido. Este enfoque concede carácter central al texto, en este caso audiovisual, y se usa para medir la frecuencia y significación de los elementos seleccionados. Entre las conclusiones más significativas de la investigación se puede destacar que la iluminación en alta definición de la séptima temporada de Amar en tiempos revueltos diferencia los distintos ambientes de la diégesis, a pesar de llevar un ritmo de producción que supera el capítulo diario. Además, la metodología propuesta es susceptible de ser marco de referencia para investigaciones futuras y posibles revisiones y discusiones de orden académico.
\end{abstract}

Palabras clave: serie de televisión; telenovela española; producción televisiva; iluminación; Amar en tiempos revueltos.

* Este artículo forma parte de la investigación para la tesis doctoral La iluminación en la ficción televisiva seriada de Televisión Española en alta definición (2008-2013), inscrita en el Programa de Doctorado en Ciencias Sociales de la Universidad Católica San Antonio de Murcia, España.

** Licenciado en Comunicación Audiovisual. Profesor asociado, Universidad Católica San Antonio de Murcia, España. Además, desarrolla su actividad profesional en el Centro Territorial de Radio y Televisión Española en Murcia, en el área de realización. Correo electrónico: gcerda@ucam.edu. Orcid: https://orcid.org/0000-0002-1363-7305 


\title{
Lighting in High Definition from the seventh season of the Televisión Española soap opera Amar en tiempos revueltos
}

\begin{abstract}
This article discusses the way in which lighting professionals articulate the expressive possibilities of light to support the Spanish production of television fiction series in high definition: How they distribute the light to adapt it to the narrative needs of the scene and the technical requirements of the television cameras. The case study chosen is the seventh season of Amar en tiempos revueltos, produced by Diagonal TV for Televisión Española, since it is one of the most successful series of Spanish television, and it exceeds the rest of national broadcast television soap operas regarding number of chapters. The theoretical foundation deficit led to in-depth interviews with directors of photography and lighting directors in these television productions. For the treatment of the data obtained (through the dialogic technique and the direct viewing of the fiction episodes), the qualitative methodology of the analysis of content was used. This approach gives a central character to the text, in this case audiovisual, and is used to measure the frequency and significance of the selected elements. Among the most significant conclusions of the research, it can be noted that the lighting in high definition of the seventh season of Amar en tiempos revueltos differentiates the environments of the diegesis, despite carrying a rhythm of production that exceeds a chapter per day. In addition, the methodology is likely to become a reference framework for future research, and for possible revisions and discussions in academia.
\end{abstract}

Keywords: television drama; spanish soap opera; television production; lighting; Amar en tiempos revueltos.

\section{A iluminação em alta definição da sétima temporada da novela Amar en tiempos revueltos, da Televisión Española}

\begin{abstract}
Resumo
No presente artigo, analisa-se a forma em que os profissionais da iluminação articulam as possibilidades expressivas da luz para apoiar a produção espanhola de ficção televisiva seriada em alta definição; como distribuem a luz para adequá-la às necessidades narrativas da cena e as exigências técnicas das câmeras de televisão. O caso de estudo escolhido é a sétima temporada de Amar en tiempos revueltos - produzida por Diagonal TV para Televisión Española — já que é uma das séries mais premiadas da Televisión Española e supera em número de capítulos o restante das telenovelas de emissão nacional. O déficit de fundamentação teórica levou a realizar entrevistas em profundidade com os diretores de fotografia e iluminadores nessas produções televisivas. Para o tratamento dos dados obtidos - por meio da técnica dialógica e do visionamento direto dos episódios da ficção - empregou-se a metodologia qualitativa de análise de conteúdo. Essa abordagem concede caráter central ao texto, nesse caso audiovisual, e é usada para medir a frequência e a significação dos elementos selecionados. Entre as conclusões mais significativas da pesquisa, pode-se destacar que a iluminação em alta definição da sétima temporada de Amar en tiempos revueltos diferencia os distintos ambientes da diegese, apesar de seguir um ritmo de produção que supera o capítulo diário. Além disso, a metodologia proposta é passível de ser ponto de referência para pesquisas futuras e possíveis revisões e discussões de ordem acadêmica.

Palavras-chave: série de televisão; telenovela espanhola; produção televisiva; iluminação; Amar en tiempos revueltos.
\end{abstract}




\section{Introducción}

La investigación de la que parte el presente artículo estudia la iluminación en la ficción televisiva seriada emitida en alta definición por Televisión Española entre los años 2008 y 2013. Se centra en las producciones que se realizan en España, y concretamente en las emitidas a través de la televisión digital terrestre por el canal TVE HD, en la cadena generalista pública nacional.

La hipótesis de trabajo sostiene que la narración condiciona la iluminación y la hace variar en su concepción, diseño, montaje, e incluso la hace evolucionar a lo largo de la diégesis. Isidro Moreno (2003, p. 84) señala que la construcción de la imagen audiovisual consta de diversos elementos, entre los que enumera la iluminación en primer término. La luz dota a la imagen de una expresividad muy diversa, según su tratamiento; transforma la puesta en escena en la que se materializa el espacio de la diégesis y llega, incluso, a crear dicho espacio en el caso de las iluminaciones espectaculares de los programas musicales o de variedades.

Así, la iluminación parece un elemento imprescindible para alcanzar un producto televisivo de calidad, pero ¿cómo se adaptan los profesionales a estos condicionantes impuestos por la narración de ficción? Con esto, el objetivo principal del estudio discutido en este artículo radicó en analizar la forma en que los directores de fotografía e iluminadores articulan las posibilidades expresivas de la luz para apoyar la producción televisiva en un caso concreto: producción de la séptima temporada de Amar en tiempos revueltos, Diagonal TV para Televisión Española.

Desde el nacimiento de los medios audiovisuales, la evolución tecnológica de los equipamientos permite el avance de las técnicas de iluminación (Chion, 1992, p. 194). En España de finales de los años 50 del siglo pasado, la premisa era aportar la suficiente intensidad lumínica mediante una iluminación precaria (García de Castro, 2002, p. 26), para que las primeras cámaras de televisión pudieran captar lo que acontecía. Actualmente, iluminadores y directores de fotografía disponen de equipamiento actualizado y profesionalidad suficientes para preocuparse por cómo se ve la imagen, tanto en términos lumínicos como colorimétricos, y centrarse en apoyar la narración. Buscan el clima, el ambiente general de la producción, para subrayar el sentido de la historia que se cuenta (Aronovich, 2005, p. 85).

Asimismo, la evolución de la iluminación de las producciones de ficción sigue en paralelo a la del resto de programas televisivos, aunque está obligada a adaptarse a los distintos decorados, tiempos o necesidades de la narración. Esta variabilidad en el diseño y ejecución de la iluminación es exclusiva de los formatos de ficción, ya que en el resto de las producciones televisivas es habitual la iluminación permanente (Millerson, 2008, p. 159). El decorado se ilumina al inicio de la emisión de los programas y la misma luz se mantiene, sin variación, durante su desarrollo. 
El estudio de la iluminación en la ficción seriada para televisión es un fenómeno complejo que se puede abordar desde diferentes puntos de vista. El primero es el examen del género de ficción y de la producción televisiva, que se concreta en las producciones seriadas de ficción televisivas. Se debe continuar con el estudio de la iluminación, desde la necesidad de iluminar en el audiovisual a la propia luz televisiva.

La producción científica en las parcelas de conocimiento relacionadas con la ficción es amplia y abundante. Pero no ocurre lo mismo con la iluminación televisiva, en la cual existen publicaciones técnicas pero las relacionadas con su función estétical son prácticamente inexistentes. Las disponibles se limitan a aportaciones en monografías técnicas, o artículos en revistas especializadas en producción audiovisual o en iluminación.

En esta introducción se pasa revista a los fundamentos teóricos utilizados en la investigación para, a continuación, centrarse en su metodología. Posteriormente se hacen públicos los resultados del análisis de la luz en la séptima temporada de Amar en tiempos revueltos y se comparten las conclusiones.

\section{Producciones seriadas de ficción para televisión}

Estos programas se caracterizan por la narración de un relato, en continuidad, a lo largo de una sucesión de episodios. Su realización precisa de una extensa producción en la que intervienen elementos narrativos, equipamientos técnicos y equipos humanos de distintas áreas. Y uno de los elementos esenciales en este tipo de producciones es la iluminación.

El estudio de la ficción seriada televisiva es abordado desde el punto de vista de los géneros televisivos por autores diversos, que aportan sus propias tipologías de género y formato (Gordillo, 1999; Amigo, 2005; Barroso, 2002; Saló, 2003; Toledano y Verde, 2007; Cortés Lahera, 2008; Carrasco, 2010). El género televisivo se define, en términos operativos, como los grandes grupos en que se clasifican los programas según su contenido temático o el público al que se dirigen (Barroso, 2002, p. 189; Castillo, 2009, p. 482). Empero, dada la tendencia televisiva a la hibridación del género, se hace necesaria la incorporación de la consideración del contenido de aquellas variaciones formales debidas a su materialización en la programación. El formato se define como el conjunto de características formales específicas de un programa que permiten su

\footnotetext{
"Iluminar es algo mucho más importante que lograr 'que se vea', entra dentro del campo de la narrativa asumiendo una doble función: técnica y estético/narrativa" (Castillo, 2009, p. 78). La función técnica se basa en proporcionar una cantidad de luz suficiente para conseguir la correcta reproducción de la imagen; mientras que la función estética de la iluminación influye directamente sobre la interpretación y reacciones del espectador: puede atraer la atención sobre un elemento o distraerla, crear un ambiente, conseguir que resulte expresivo, bello o, simplemente, adecuado a los fines narrativos de la diégesis.
} 
distinción y diferenciación con respecto a otros, sin necesidad de recurrir al contenido como criterio de demarcación (Carrasco, 2010, p. 180).

El resto de los conceptos significativos para el presente estudio se agrupan bajo la denominación de 'estándares de producción': "aquellos parámetros creativos, técnicos y logísticos que condicionan el proceso de producción en sus variables típicas (tiempo, coste y calidad) y permiten desarrollar un sistema de producción seriada a gran escala" (Diego y Pardo, 2008, p. 46; Diego, 2010, p. 89).

\section{La iluminación en televisión}

Será necesario [...] armonizar los contrastes (cantidad relativa de luz entre luces y sombras), la orientación (altura, dirección), la temperatura de color $\left[\mathrm{T}^{\mathrm{a}}\right]$, la naturaleza del haz (direccional como el sol o difuso como en días cubiertos). (Loiseleux, 2005, p. 31)

En gran medida, el resultado final de la imagen de las producciones audiovisuales es responsabilidad de los profesionales de la iluminación, iluminadores y directores de fotografía. Su labor es distribuir la luz para lograr imágenes adecuadas frente a las necesidades de la escena y las exigencias de las cámaras (Cebrián, 1981, p. 185).

La captación de la realidad por parte de las cámaras presenta diferencias profundas respecto al modo en que lo hace el sistema visual humano, las cuales impiden la adecuación de la luz habitual para el registro audiovisual. El cerebro humano "inventa un mundo visual" (Zeki, 2002, p. 70) cuando adquiere conocimiento del mundo exterior mediante los estímulos visuales que los ojos le transmiten. Pero la cámara no posee estas constantes perceptuales humanas; así si se produce una variación de la dirección de la luz, su intensidad o su color la refleja la imagen. Para superar estas diferencias, la iluminación en el audiovisual debe ser concebida, proyectada y ejecutada desde dos parámetros fundamentales: los tratamientos lumínico (la cantidad de luz) y colorimétrico (la calidad de luz).

Respecto a la cantidad de luz se decide qué partes de la escena se registran correctamente y en qué medida. Para lograrlo se actúa sobre la orientación (horizontal y vertical) e intensidad de las diferentes fuentes de luz, y sobre la naturaleza de su haz ${ }^{2}$. La luz televisiva hereda de la cinematográfica, toma prestadas sus técnicas de iluminación más eficaces de la fotografía, básicamente las del retrato, ya que el rostro humano es siempre el centro de atención. Una de ellas es conocida como la técnica de

\footnotetext{
Una fuente de luz dura, o puntual, es direccional, arroja sombras nítidas y bien definidas, revela la textura y los contornos de la superficie al crear un modelado marcado, bien definido mediante altos contrastes. Por el contrario, una fuente de luz suave, o difusa, no es direccional ni admite una fácil limitación, disminuye el contraste y crea ambientes más abiertos (Millerson, 2008, p. 66; Bermingham, 2010, p. 104).
} 
las cuatro luces ${ }^{3}$. Mediante la correcta ubicación de cuatro fuentes de luz — contraluz, luz principal, de relleno y de fondos - se obtiene el máximo rendimiento expresivo para una toma continua con varias cámaras sobre un tema tridimensional.

La luz principal determina la exposición, marca la dirección general de la iluminación y crea el modelado mediante las sombras. Habitualmente se sitúa frente al sujeto, y su angulación ideal respecto al eje de la cámara —en horizontal — varía entre $0^{\circ}$ y $45^{\circ}$. Su altura viene limitada por la sombra que proyecta la nariz sobre los labios y la posibilidad de cortar la luz que incide sobre los fondos. Por el contrario, el contraluz se consigue mediante una fuente luminosa colocada tras el sujeto; da profundidad a la imagen en tanto separa personaje y fondo, y acentúa su contorno. La luz de relleno, proporcionada por una fuente difusa, se distribuye de manera homogénea para controlar la relación de contraste ${ }^{4}$ de la escena; atenúa las sombras demasiado evidentes y los contrastes excesivos debidos a la luz principal. Normalmente se coloca frente al sujeto y lo más baja posible, casi a la altura de la cámara. La luz de fondos, a su turno, se utiliza para iluminar el decorado; debe ser independiente de la que recibe el sujeto, y no influir sobre la iluminación de este.

Se utiliza el término clave para describir el ambiente de una imagen, la distribución de tonos y el contraste tonal (Bermingham, 2010, p. 21). Habitualmente se diferencia entre la iluminación en clave alta y en clave baja (expresión desafortunada por la simplificación del trabajo de los profesionales que conlleva), tipología que Alan Bermingham amplía con la inclusión de la clave media -iluminación que tiene una distribución de tonos normal- En el caso de la clave alta hay un predominio de tonos claros y sombras tenues, se obtiene una imagen ligera casi bidimensional. Se inunda de luz todo el espacio habilitado para que deambulen los personajes. La iluminación en clave baja tiene un predominio de los tonos oscuros y las sombras densas. Se ilumina a partir de la oscuridad completa y el resultado es una imagen de apariencia dramática muy sólida. Se utiliza, sobre todo, en programas relacionados con la ficción.

Respecto a la calidad de luz $z^{5}$, los profesionales de la iluminación han de controlarla para conseguir una imagen natural o expresiva. La cámara reproduce tonalidades distintas para cada tipo de luz blanca utilizada en función de su espectro lumínico, de las longitudes de onda que la componen. Para conocer la reproducción cromática

También se la denomina "iluminación de tres puntos" o "triángulo básico de iluminación" cuando no se alude al uso de la luz de fondos.

$4 \quad$ La diferencia entre la mayor y la menor luminosidad de una escena se denomina relación de contraste. Si dicha diferencia supera la aceptada por la cámara, la escena no se puede reproducir en su totalidad. Aquello que no recibe la iluminación mínima queda subexpuesto, en la oscuridad. Si recibe una iluminación superior a la admitida, queda sobreexpuesto y su imagen aparece quemada.

5 El concepto de calidad de luz puede ser utilizado desde dos puntos de vista: como la naturaleza del haz de luz -duro o difuso- o como su naturaleza colorimétrica. Esta segunda acepción es la adoptada en la presente investigación. 
se utiliza la magnitud temperatura de color. Cuanto más elevada es la tensión con que se alimenta una lámpara incandescente, mayor es la temperatura de su filamento, y su espectro cromático varía de tonalidades cálidas a cada vez más frías. Así, es posible asociar los tipos de luz a la temperatura correspondiente —-medida en grados Kelvin $\left({ }^{\circ} \mathrm{K}\right)$ - a la que funciona en el filamento de una lámpara modelo para suministrar una luz cromáticamente análoga a la estudiada (Millerson, 2008, p. 361; Bermingham, 2010, p. 62). Respecto a la calidad de luz, se deben corregir los efectos indeseables causados por la iluminación de una escena con un tipo de luz de calidad distinta a la que está ajustada la cámara. Estas vienen ajustadas de fábrica para la luz de tungsteno halógeno $\left(3200^{\circ} \mathrm{K}\right)$. Y además pueden trabajar con luz día $\left(5600^{\circ} \mathrm{K}\right)$ mediante el ajuste del balance de blancos ${ }^{6}$.

El iluminador, o el director de fotografía confiere el tono visual a la obra que es fundamental para la narración. Una actitud clásica respecto a la calidad de luz le lleva a compensar cualquier desviación de la temperatura de color. Sin embargo, las últimas tendencias en iluminación consienten las diferencias de temperatura de color -interior, exterior o de cualquier otro tipo- utilizándolas, incluso, como valor expresivo. Sobre esta forma de actuar se propone una tipología de creación propia que relaciona la colorimetría de las fuentes y el ajuste de cámara: así, la corrección es total si la luz proveniente de los diferentes proyectores no presenta coloración para la cámara; parcial, si el filtrado es distinto para las diferentes luminarias, se consiente la mezcla de luces; o dominante si se busca una determinada coloración, una dominante de color en toda la imagen.

Además, cuando se ilumina una localización, sobre todo en la ficción, se tiende a justificar la luz a la búsqueda de un mayor realismo. Los profesionales de la iluminación se preocupan por motivar el origen de las fuentes de luz tanto en cantidad como en calidad. De este modo buscan las posibles fuentes presentes en el decorado, o las propias del interior natural, para hacer incidir la luz desde su ubicación y con la colorimetría correspondiente. Pueden ser ventanas, puertas o claraboyas en el caso de escenas de día, o velas, lámparas, chimeneas, etc. en el caso de la noche.

\section{Amar en tiempos revueltos}

Este artículo se centra en el análisis de la iluminación en la última temporada de Amar en tiempos revueltos, la única de las siete temporadas de este serial emitido por Televisión Española que se produce en alta definición. Sus emisiones comenzaron de forma simultánea en La 1 y en el canal TVE HD, el lunes 5 de septiembre del 2011.

\footnotetext{
$6 \quad$ Este ajuste permite compensar cualquier desviación que se pueda producir en la temperatura de color mediante el control de la ganancia de los canales RGB (rojo, verde y azul) de la cámara electrónica (Castillo, 2009, p. 319).
} 
La telenovela se emite de lunes a viernes en la programación de sobremesa de la cadena pública nacional. Comienza inmediatamente después del informativo Telediario-1 y El tiempo. Sus emisiones finalizaron el lunes 15 de noviembre de 2012. Además, sus dos episodios finales se programaron no solo en su horario habitual, sino también en prime time, tras el Telediario-2 y la información meteorológica nocturna. Su secuela, Amar es para siempre, continúa en la actualidad sus emisiones en la cadena privada nacional Antena 3 (RTVE, 2012).

Amar en tiempos revueltos es una de las series más laureadas de Televisión Española: supera la quincena de galardones, tanto nacionales como internacionales. Durante sus siete temporadas consiguió una media de share del $20 \%$ y alcanzó picos del 29,9\% (3.068.000 espectadores) (Diagonal TV, 2005-2012). El número de capítulos desde el comienzo de sus emisiones, el lunes 26 de septiembre de 2005, hasta su finalización, llegó a 1.716. Si a esta cifra se le añaden los más de 1.400 emitidos en Antena 3 bajo la denominación Amar es para siempre —en el momento de la redacción de este artículo_-, el total de episodios asciende a más de 3.100. Esta cifra supera a todos los seriales vespertinos de las televisiones nacionales ${ }^{7}$, aunque entre los emitidos por las televisiones autonómicas se encuentra la producción seriada de ficción más longeva de España: Goenkale, producida por Pausoka Entertainment para Euskal Telebista, que permaneció durante 21 años en el canal autonómico vasco y alcanzó la cifra de 3.707 capítulos.

\section{Metodología}

La falta de fundamentación teórica relacionada con la iluminación en televisión condujo a realizar una serie de entrevistas en profundidad (del 2009 al 2014) con directores de fotografía e iluminadores de las producciones de ficción televisiva seriada española. Su preparación se fundamentó en un cuadernillo de elaboración propio con los temas fundamentales, obtenidos del análisis de las fuentes teóricas disponibles, que se debían abordar mediante preguntas abiertas.

Como las entrevistas se desarrollaron en las instalaciones en las que se grabó, se realizó una observación directa (Rincón, Justo, Latorre y Sans, 1995, p. 227) de los procesos y estándares de producción. Dado que en la utilización de los instrumentos de análisis basados en la observación directa "el investigador no puede 'eliminar' su presencia" (Casetti y di Chio, 1999, p. 24), se aprovechó la experiencia profesional propia para obtener la máxima información de la visita a los estudios de producción de las series y la conversación con sus profesionales.

La telenovela cuyas cifras se le aproximan es El secreto de Puente Viejo -producida por Boomerang TV para Antena 3-. Supera los 1.800 episodios emitidos en el momento de la redacción de este artículo. 
Las técnicas anteriores se encaminan al análisis de contenido de la iluminación en la ficción televisiva seriada emitida en alta definición por Televisión Española. Se pretende poner de relieve determinados elementos del texto, en este caso audiovisual. Son las unidades de registro de las que, una vez extraídas del corpus, se debe medir su frecuencia y, por tanto, su significación (Navarro y Díaz, 1994, p. 192).

Las operaciones clave en el análisis de contenido comenzaron con la definición del problema y la formulación de hipótesis, ya descritas en la sección introductoria de este documento. Se continúa con la definición de las unidades de clasificación con elementos útiles para la investigación, extraídas del vaciado bibliográfico, y la preparación de la ficha de análisis de elaboración propia. Solo resta la elección del corpus de textos sobre los que se va a trabajar y la aplicación de la ficha de análisis para computar los resultados.

En el presente caso de estudio, el corpus lo componen las emisiones de la séptima temporada de Amar en tiempos revueltos. Pero sus episodios superan los doscientos, son de extensa duración y cuentan con variedad de localizaciones. Además, en cada decorado interior, interior natural o localización exterior se adopta un nuevo esquema de iluminación o varios, si en ese mismo lugar la narración se desarrolla de día y de noche. Este hecho hace imposible un análisis de todo el corpus de estudio. Se debió aplicar una selección para obtener una muestra representativa y lograr que los resultados fuesen concluyentes.

\section{Selección del corpus}

El guion es la forma escrita de una narración audiovisual (Castillo, 2009, p. 24). El plan fundamental de una producción seriada de ficción televisiva que articula cada capítulo en secuencias, escenas y planos, y en esta articulación se debe buscar la selección útil para el análisis de la luz. La secuencia es la gran división de la narración con sentido pleno. Habitualmente está constituida por un conjunto de escenas que forman una unidad de acción dramática completa unificada por una sola idea (Field, 2002, p. 86). Y, a su vez, las escenas están constituidas por una sucesión de planos, la unidad elemental de la narración. Cada uno de los fragmentos de la toma registrada por la cámara que, posteriormente, es elegido en el montaje para su incorporación al discurso narrativo.

Se define la escena como la acción continuada registrada en un mismo ambiente, o escenario, que carece de sentido completo (Castillo, 2009, p. 26), y cuyo objetivo clásico es hacer progresar la historia. Por lo tanto, "tiene lugar en un lugar determinado y a una hora determinada" (Field, 2002, p. 118). Es en esta concreción espacial y temporal donde se encuentra la división adecuada para el estudio de la luz. 
Asimismo, la redacción de las escenas inicia con el encabezado, escrito en mayúsculas y separado por un doble espacio - o una línea continua, más habitual en los guiones de las series españolas - de la descripción de la acción y los diálogos de la escena. Incluye la numeración de la escena, si se desarrolla en interior o exterior, la localización donde se desarrolla la acción y la información del momento de la jornada en el que transcurre la escena, el efecto de luz.

Además, para el estudio de su iluminación no es preciso llegar al análisis de cada plano, por tratarse de una labor demasiado fragmentaria y prácticamente inabarcable. De hecho, las producciones de la ficción seriada nacional se realizan con técnica multicámara ${ }^{8}$ para agilizar su producción. Se ilumina el decorado donde se desarrolla la acción en continuidad y las cámaras la captan simultáneamente en los diferentes encuadres solicitados por el realizador; y esta acción continuada coincide con el concepto de escena.

La división en escenas también puede conseguirse mediante el visionado de los episodios de la producción de ficción, dado que "si se cambia el lugar o el tiempo, se transforma en otra escena" (Field, 2002, p. 118), se visiona el capítulo para encontrar los cambios de localización que se producen, aun los temporales - aunque de estos hay una menor frecuencia en la ficción televisiva española—.

Sea que se obtenga el número de escenas ${ }^{9}$ o bien del guion, o bien mediante visionado, a continuación se agrupan según la localización donde se graba, de forma similar a como se estructura el plan de trabajo para obtener la máxima economía de tiempo (Jacoste Quesada, 1996, p. 133; Sainz, 2002, p. 221). Los productores realizan primero el desglose del guion en escenas o secuencias mecánicas ${ }^{10}$ para agrupar las sesiones de trabajo por escenario y luego por intérpretes. Se debe establecer una diferencia entre los números de escenas totales y agrupadas, según la localización. Además, debe establecerse si la escena se graba en interiores, interiores naturales o exteriores. Y el efecto de luz: día, noche, o las menos habituales: amanecer, atardecer y noche americana (Loiseleux, 2005, p. 35).

La técnica multicámara "implica la utilización de al menos dos cámaras cuyas imágenes son seleccionadas y mezcladas durante el desarrollo del acontecimiento con la intervención de un mezclador de imagen a fin de obtener una continuidad secuencial y narrativa de las imágenes seleccionadas" (Barroso, 2002, p. 46). Aunque en la práctica se denomina así a la producción en la que más de una cámara registra los distintos campos de la misma escena, lo más común son tres, aunque no siempre se incluye la mezcla en directo.

9 El cómputo total de escenas debe incluir la cabecera y los créditos finales, así como las escenas de apertura que suelen remitir a episodios anteriores y los avances de capítulos futuros. Pero se les da el valor de una escena, aunque incluyan varias localizaciones -son elementos que no suelen figurar en el guion de la ficción, se incorporan en la fase de postproducción-; y se les asigna por defecto los valores interior/día como más habituales, a fin de no desvirtuar el tratamiento estadístico de los datos.

10 "Una secuencia dramática puede comprender varias secuencias mecánicas, que se corresponden con la parte de la acción que se desarrolla en un mismo escenario sin que se produzcan saltos de tiempo" (Jacoste Quesada, 1996, p. 130). 
La herramienta elegida para la selección es el muestreo aleatorio estratificado. En él se separan los elementos de la población en grupos no solapados en función de un carácter determinado, llamados estratos, para la posterior selección de una muestra irrestricta aleatoria simple de cada estrato (Scheaffer, Mendenhall y Lyman, 2006, p. 126). En el caso de estudio, la división en estratos de las escenas agrupadas se realiza en función de la localización de la grabación y los distintos efectos de luz, anteriormente descritos. Asimismo, la selección ha de realizarse de forma preferente por los datos significativos que pueden aportar, entre las escenas que cuentan con variaciones en el efecto de luz en la misma localización.

Tras las consideraciones anteriores se optó por estudiar tres escenas del primer episodio de la séptima temporada de Amar en tiempos revueltos ${ }^{11}$. Este capítulo se articula en 41 escenas (que incluyen cabecera y créditos de salida con el avance del próximo episodio, y cuatro escenas montadas con imágenes de archivo del NO-DO'2) grabadas en 20 localizaciones diferentes. El episodio consta de 33 escenas en interiores (incluidos cabecera, créditos de salida y una de las montadas con imágenes de archivo), ninguna en interiores naturales, y 8 en exteriores - tres del NO-DO- Respecto a la luz, son 33 las escenas de día (se incluyen nuevamente cabecera, créditos de salida y dos de las escenas de archivo), 7 nocturnas — una del NO-DO- y una que puede ser considerada como atardecer, editada con imágenes de archivo.

Como quedaron fuera las escenas que no fueron grabadas por el equipo de producción de la ficción —las del NO-DO anteriormente citadas-, el número de escenas agrupadas se redujo a 14. Asimismo, el capítulo incluye entre las escenas agrupadas dos decorados que se muestran tanto de día como de noche: el Salón de Chelo y la redacción de la revista Sucesos ${ }^{13}$. Por lo tanto, la elección para el análisis se debió realizar entre ellas, y dado que ambas se desarrollaban en interiores, la tercera se decidió por aleatoriedad simple entre las escenas grabadas en exteriores. El resultado de esto es que se debió analizar la localización interior redacción de la revista Sucesos, concretamente las escenas 10 (día) y 36 (noche); la tercera, exterior, fue la escena 5, Tetuán, 1947.

"I El episodio está disponible en http://www.rtve.es/alacarta/videos/amar-en-tiempos-revueltos/amar-tiempos-revueltos-t7capitulo-1/1189920/.

12 El NO-DO, acrónimo de Noticiarios y Documentales Cinematográficos, se creó durante la dictadura del general Francisco Franco como un servicio semanal de difusión de noticiarios y reportajes filmados de obligatoria exhibición en los cines de España, posesiones y colonias. Se proyectaba antes de la película de 1943 a 1975 obligatoriamente, y de forma voluntaria hasta su cierre en mayo de 1981 (http://www.rtve.es/filmoteca/no-do/).

13 La división en escenas agrupadas de Amar en tiempos revueltos T.07 C.01 se obtiene del visionado directo del capítulo. Por lo tanto, se nombran según los datos obtenidos de la propia diégesis: el nombre del personaje que reside en la vivienda, el lugar de trabajo, la calle donde se desarrolla la acción.. 


\section{La ficha de análisis}

La elección de las unidades de clasificación de la ficha de análisis, con los elementos precisos para la investigación, se basó en el Modelo de análisis de la imagen fotográfica del grupo de investigación Itaca de la Universitat Jaume I (Marzal, 2004). La adaptación del modelo tiene en cuenta las diferencias entre la televisión y la fotografía estática, por lo que incluye solo los parámetros aplicables. También debe contener la clasificación de los formatos de los programas seriados de ficción enunciada en la investigación principal. Así como el concepto de estándares de producción propuesto por Patricia Diego y Alejandro Pardo (2008, p. 46) para definir los parámetros creativos, técnicos y logísticos que condicionan el proceso de producción de un programa televisivo. De este modo, la ficha se estructuró en cuatro epígrafes: contexto, género de ficción, producción e iluminación.

En el nivel de contexto se describieron los datos generales de la producción, su equipo humano y equipamiento técnico. Por razones operativas no fue posible incluir a todo el equipo humano, así que se enumeraron sus integrantes más significativos: los jefes de equipo de producción, dirección y los directamente relacionados con la construcción de la imagen — direcciones de arte y fotografía—, además de los intérpretes más destacados.

El nivel del género de ficción contiene los epígrafes de temática y formato. Es innecesario señalar el primero en una investigación que se centra en la ficción, no así el segundo. La ficha incluye las condiciones excluyentes que debe cumplir la producción de ficción para incluirse en una de las categorías de la tipología de elaboración propia:

- TV-movie: producción de ficción unitaria.

- Miniserie: producción seriada de ficción con menos de 13 capítulos.

- Serie: producción seriada de ficción dramática de emisión semanal.

- Telenovela: producción seriada de ficción dramática de emisión diaria.

- Comedia de situación: producción seriada de ficción cómica en decorado único y con un número de personajes fijo y limitado.

El nivel de producción, a su turno, enumera los conceptos de los estándares de producción. Son los parámetros más difíciles de conseguir, dado que no pueden ser obtenidos del visionado y análisis de los episodios. Se pueden obtener de informaciones aparecidas en los medios de comunicación, mediante la técnica dialógica de la entrevista, o a través de la observación directa. No obstante, para alguno de ellos no hay más remedio que recurrir a las empresas productoras o a las propias emisoras de televisión que, muchas veces, son reacias a proporcionar dichos datos. 
En el nivel de iluminación se analizan las características de la luz de la escena desde lo genérico — el estudio cualitativo global de la iluminación- a lo específico -el estudio individualizado, casi cuantitativo, de las cuatro luces-. De este análisis individual -desde los puntos de vista lumínico y colorimétrico- se pasó al análisis global del capítulo.

\section{Resultados}

\section{Nivel de contexto}

La duración del primer capítulo de la séptima temporada de Amar en tiempos revueltos asciende a 46 minutos y 13 segundos. En esta producción los episodios no tienen título propio, el estudiado comienza con una secuencia de archivo del noticiario cinematográfico español NO-DO sobre la que se rotula el lugar y año de la acción, que enlaza con la introducción previa a la cabecera. La frecuencia de emisión es diaria y la fecha de producción del capítulo es julio de 2011 (entrevista Altable, 2012).

Este serial es producido por Diagonal TV, en la actualidad integrante del Grupo Endemol España, para Televisión Española, y se inspira en Temps de silenci — Diagonal TV para TV3 - : esta serie semanal para la televisión autonómica catalana, basada en una idea original de Rodolf Sirera, permaneció en antena entre enero de 2001 y abril del 2002 en horario de prime time.

El equipo humano está encabezado por Jaume Banacolocha y Joan Bas (socios fundadores de Diagonal TV) como productores ejecutivos y Montse García, que en los créditos iniciales del capítulo figura como "producción ejecutiva adjunta". Los directores de producción son Eugeni Margalló y Nuria Hernández; el jefe de producción es David Larios; María Roy es delegada de producción de Televisión Española; en la idea y argumento aparecen Josep M. Benet i Jornet, Antonio Onetti y Rodolf Sirera; el director de la serie es Eduardo Casanova, también director-realizador del episodio analizado; los responsables de la dirección de arte son Marcelo Pacheco, Virginia Flores y Yolanda Moreno; el diseño de iluminación es obra de Fernando Gallego, Carlos R. Valera, José Altable y Aldo Basso, y la iluminación del capítulo es responsabilidad de Carlos R. Valera (en los créditos como "director de fotografía 1. a unidad") y José Altable (como "director de fotografía 2. a unidad").

Los principales intérpretes, por orden de aparición en los rótulos de la cabecera, son Natalia Millán, Alberto Jiménez, Natalia Sánchez, Lola Baldrich, Manuel Baqueiro, Itziar Miranda y José Antonio Sayagués, con la colaboración especial de Joaquín Climent y Juanjo Puigcorbé. En cuanto al equipamiento técnico se utilizan camascopios ${ }^{14}$

Camascopio: cámara + magnetoscopio. Adaptación al castellano del término anglosajón camcorder que designa las cámaras autónomas -camera- que cuentan con un magnetoscopio grabador -recorder-en su construcción. 
Panasonic AJ-HPX3100 con objetivo zoom, y el soporte de registro es videográfico en alta definición —-formato 25p (progresivo) — mediante grabación directa en servidor de video. La postproducción se realiza en editores no lineales Avid Media Composer y el etalonaje en Avid Symphony.

\section{Nivel del género de ficción}

"En Tetuán, 1947, un niño, el hijo del Capitán Robledo, recibe un extraño encargo de su padre antes de suicidarse. Nos trasladamos unos años después, tras la independencia del protectorado español de Marruecos" (TVE, 2011). De esta sinopsis del episodio se deduce que la producción es un drama, y dado que cumple con la condición excluyente de ser una producción seriada de ficción dramática de emisión diaria se clasifica como telenovela.

\section{Nivel de producción}

El presupuesto medio por capítulo se sitúa alrededor de los $56.000 €$ (Migelez, 2013), para un serial dirigido al público objetivo propio de la primera parte de la sobremesa. Se trata de un target mayoritariamente femenino (López-Pumarejo, 1987, p. 25) que se concreta en las mujeres que trabajan en casa (Chicharro y Rueda, 2008, p. 72).

La telenovela puede ser considerada, en referencia a sus personajes, como una narración coral compuesta por múltiples tramas. El número total de episodios producidos asciende a 1.716 (incluidos los cuatro capítulos dobles especiales y el episodio resumen de la primera temporada, emitido el 23 de junio de 2006). La séptima temporada, a su turno, está compuesta por 256 capítulos, y el episodio analizado es el 1.457 en el cómputo global.

El plan de trabajo se estructura en dos platós independientes, situados en la Ciudad de la Imagen de Madrid y concretamente en Cars Estudio, donde están construidos tanto los decorados interiores y exteriores más habituales. La distribución de localizaciones puede dividirse entre un 70-80 \% de grabación en plató y un 20-30 \% en Exteriores -el porcentaje de interiores-exteriores en el episodio analizado es del $80 \%-20 \%$ - Las escenas exteriores se graban en los decorados construidos en el mismo estudio, aunque en ocasiones también se rueda en otras localizaciones.

Se cuenta con dos unidades de producción, cada una equipada con tres camascopios Panasonic AJ-HPX3100 con objetivo zoom. Los soportes de cámara utilizados varían entre las dos unidades, según las necesidades fijadas por el director-realizador. "La unidad dos trabaja con tres cámaras ya sea en hombro, en trípode o con dos cámaras y un steadicam. La unidad uno suele trabajar con dos cámaras en trípode y una pequeña grúa, una mini jib" (José Altable Balcones, comunicación personal, 2012). 
Aunque los camascopios están equipados con tarjetas de memoria DVCPRO P2, se opta por la grabación directa en servidores de vídeo ${ }^{15}$ para agilizar la posproducción. De este modo, cuando es dada por buena la grabación de la escena, puede iniciar el montaje en las estaciones de edición no lineal Avid Media Composer disponibles en Cars Estudio.

El etalonaje se realiza en las mismas instalaciones con Avid Symphony. Como se trata de una producción de emisión diaria el tiempo, los recursos dedicados a la postproducción de la luz no son excesivos. Se utiliza para "igualar secuencias Interior, Exterior, dar un mejor acabado, pulir planos que pueden estar un poco oscuros, un poco altos (...)" (José Altable Balcones, comunicación personal, 2012).

Este método de producción industrial, como lo definió José Altable en la primera visita a los estudios de grabación (Entrevista Altable, 2009), permite la producción de un capítulo diario. Las escenas diarias grabadas superan la treintena, alrededor de quince para cada unidad de producción. Aunque, como lo señaló Carlos R. Valera, en la séptima temporada de Amar en tiempos revueltos "llevamos una producción últimamente más apretada" y se llegó a producir más de un episodio diario (Carlos R. Valera, comunicación personal, 2012).

\section{Nivel de iluminación}

Las tres escenas seleccionadas se analizan a continuación en orden cronológico.

\section{Análisis de la Escena 5: Tetuán, 1947. Exterior/día}

Esta es la quinta escena del episodio, tras el arranque y la cabecera. Se localiza en unos jardines árabes de Toledo (entrevista Altable, 2012). En la diégesis se sitúa, mediante rotulación sobreimpresionada, como Protectorado español en Marruecos. Tetuán, 1947. Es una escena exterior/día, grabada en plano único y con una duración de 33 segundos. Los personajes que aparecen son Aisha, la criada árabe, y Carlos, el hijo del capitán Robledo, además de la figuración infantil.

La acción dramática de la escena se centra en los niños que juegan en el jardín, y los soportales, cuando Aisha viene a recoger a Carlos para que suba a casa. En cuanto a su descripción técnica, la escena abre de negro tras la cabecera. Está grabada con una sola cámara, montada en steadicam, que sigue a los niños. Aisha sale del portal y le dice a Carlos que suba a casa. Encadena a la escena 6 con Carlos mientras hace sus deberes.

15 En interiores o en los exteriores del estudio se utiliza el servidor de video, pero la grabación continúa en las tarjetas cuando se sale a otros exteriores no habituales. 
En la escena, el sol entra en los soportales de la casa árabe a través de las arcadas, en un análisis global de la iluminación. Probablemente las marcas de altas luces en el suelo están realizadas con proyectores, y otro montaje de proyectores de luz difusa rellena la zona donde se desarrolla el final de la escena.

La relación de contraste de la escena es elevada. Así, el exterior, visto a través de los soportales, está sobreexpuesto — prácticamente quemado- — el zaguán casi en sombras. Aunque la relación de contraste de la zona donde se desarrolla el final de la acción es baja, en clave baja. La luz utilizada es difusa en general, aunque las marcas en el suelo de los haces que entran por los soportales son bastante duras. La corrección de la colorimetría en la escena es total: no se aprecian dominantes de color evidentes. La justificación del diseño de la iluminación se basa en la entrada de luz a través de las arcadas, tanto en la cantidad de luz como en la ausencia de diferencias colorimétricas.

El análisis individualizado de la técnica de las cuatro luces debe iniciarse con la descripción de las posiciones relativas de los personajes y los proyectores en los planos generales presentes en la escena. Pero en este caso, el movimiento circular del travelling hace difícil ubicar las luces en el eje horizontal. La dirección de la luz principal viene desde el exterior de los arcos con una altura no excesiva, probablemente con proyectores —o palios reflectores - montados en trípode a unos $30^{\circ}$ en altura. Su luminosidad, medida ${ }^{16}$ sobre las luces en la camisa blanca del niño de primer término en la ubicación final, es del 91 \%. Es una luz dura, justificada por su procedencia desde el exterior de los arcos. La medida colorimétrica, 232R 225G 218B, no indica dominantes, por lo que los posibles proyectores están filtrados a luz día, $5600^{\circ} \mathrm{K}$.

No se aprecia la presencia de contraluces, y parte de la luz de relleno proviene del reflejo solar que entra por los arcos. Además, probablemente se realiza un montaje de luces difusas para rellenar desde el interior de los arcos. Por las características de la escena es difícil ubicar la procedencia horizontal del relleno, mientras que su altura se sitúa a la de cámara, $0^{\circ}$. Su luminosidad, medida sobre las sombras de la camisa blanca del mismo niño, es del $66 \%$ ( $25 \%$ por debajo de la luz principal). Es una luz difusa, justificada por la reflexión de la luz del sol en el exterior. Se puede observar la ausencia de dominantes colorimétricas en su medida, 169R 151G 134B, que conlleva el filtrado total a $5600^{\circ} \mathrm{K}$.

Para la toma de medidas se hace uso de la herramienta "cuentagotas", incluida en los programas informáticos de tratamiento de imagen. Se utiliza Adobe Photoshop porque proporciona datos en diferentes modelos de color y permite, incluso, tomar muestras directamente del vídeo sobre la pantalla del reproductor multimedia. Así, del modelo de color HSB se extraen los datos de luminosidad en porcentajes, mientras los datos de colorimetría se obtienen del modelo RGB que los expresa en 255 niveles para cada color. De este modo se pueden enunciar conclusiones cualitativas a partir de muestras cuantitativas tomadas siempre sobre la misma superficie, preferentemente blanca ya que proporciona medidas de luminosidad próximas al $100 \%$. 
La única luz de fondos se aprecia en el zaguán de entrada a la casa. El suelo y la cómoda quedan marcados por una luz dura, situada a $90^{\circ}$ a la derecha y a una altura de unos $20^{\circ}$. Su luminosidad, medida sobre las altas luces que inciden en el dintel de una ventana del zaguán, es del $44 \%$. No obstante, no es posible considerar que la luz de fondos sea aproximadamente la mitad de la luz principal, sino similar, puesto que se mide sobre un dintel de ladrillo pardo y no en una superficie blanca. Se simula una ventana a la derecha del zaguán con una luz dura totalmente corregida a $5600^{\circ} \mathrm{K}$.

\section{Análisis de la escena 10. Redacción de la revista Sucesos, interior/día}

La narración salta a 9 años después mediante una elipsis temporal indicada por sobreimpresión. Este título, en la escena 9, sitúa el resto del capítulo en Madrid, junio de 1956. La décima escena se desarrolla en la redacción de la revista Sucesos, decorado habitual en la séptima temporada de la telenovela que está construido en Cars Estudio. Es una escena interior/día articulada en 22 planos, con una duración de 1 minuto y 8 segundos. Los personajes que intervienen son Adolfo, director de la publicación Adolfo; Jesús, el redactor jefe, y Julio, el dibujante, junto a la figuración de periodistas.

En la descripción dramática el dibujante prepara una ilustración, siguiendo las indicaciones del redactor jefe, a la espera de la sentencia absolutoria de un juicio. Aunque tiene lista otra, ordenada por el director, que ilustra el ajusticiamiento mediante garrote vil. Tras darse cuenta de su diferencia de opinión, los dos jefes inician una discusión por la posible sentencia.

Técnicamente la escena inicia con un travelling de retroceso desde un plano detalle del dibujo a la conversación entre redactor jefe e ilustrador. Se sigue la técnica del plano-contraplano, con las cámaras a alturas diferentes (dibujante sentado y redactor jefe de pie). Cuando entra el director en la redacción se vuelve a un plano general con el steadicam, y las cámaras del plano-contraplano — ahora a la misma altura — se centran en la conversación de pie entre redactor jefe y director. Cuando enfilan el pasillo que lleva al despacho del director el steadicam les sigue en travelling. A las escenas anterior y posterior se pasa por corte.

La luz de la redacción proviene, en términos globales, del fondo del decorado: allí hay una fila de lámparas suspendidas y la luz principal actúa también de contraluz. La escena se rellena con luz difusa para permitir el paso del steadicam, siguiendo la técnica de las medias luces retrasadas ${ }^{17}$, y evitar sus sombras y las de las pértigas de sonido. Por las ventanas de la derecha entra luz a través de unas vidrieras, con lo que

17 Los iluminadores de Televisión Española denominan con el término 'medias luces retrasadas' al diseño en el que se ilumina de atrás hacia adelante. La luz principal viene desde la posición contraria a la cámara, $180^{\circ}$-lo que hace innecesario el contraluz-, y el relleno se sitúa de frente, a $0^{\circ}$ del ángulo de cámara. De este modo, la sombra de la jirafa va a caer fuera de campo y es muy difícil que se vea (entrevista Blanco y García, comunicación personal, 2010). 
se simula la luz solar y se marcan paredes y techo. Se ilumina en clave baja mediante luces difusas, a excepción de las marcas del símil de luz solar en paredes y suelo. La justificación de la dirección de la luz, con las ventanas y lámparas del decorado, es total en cuanto a su cantidad. La corrección total de la colorimetría de la escena interior/día no precisa de justificación.

Para el análisis individualizado se tomó como referencia el plano general de la cámara montada en el steadicam. Así, la puerta del pasillo queda al fondo, y la luz principal viene de esa dirección, a $180^{\circ}$, situada a una altura mayor de $45^{\circ}$, unos $60^{\circ}$, como indican las sombras de la nariz de los actores sobre sus labios.

Para las medidas lumínicas y colorimétricas se recurre a la camisa del redactor jefe. Aunque no es totalmente blanca, la ausencia del director (vestido con una camisa blanca) en la siguiente escena impide la comparación directa entre ambas. La luminosidad es del $85 \%$. Su luz difusa queda justificada, al igual que su ubicación e intensidad, por las lámparas del fondo de la redacción. La corrección de su temperatura de color es total, 218R 207G 199B.

No se precisa de iluminación de contraluz diferenciada. La luz de relleno ilumina desde la posición de cámara, $0^{\circ}$ horizontales y verticales, y su luminosidad, medida sobre las sombras en la misma camisa, es del $41 \%$-un $44 \%$ menor que la principal-. Es una luz difusa con una corrección total de su temperatura de color, 105R 101G 91B.

Sobre el fondo solo incide el símil de luz solar que entra por las ventanas de la derecha. El proyector que la imita está situado $90^{\circ}$ a la derecha, a una altura de $50^{\circ}$ $60^{\circ}$. Su luminosidad, medida sobre las altas luces que marcan la pared, es del $97 \%$ $-12 \%$ superior a la de la luz principal—. La proporciona un proyector de luz dura, aunque las vidrieras la difunden un tanto, que queda justificada como luz solar.

La vidriera dificulta la medida colorimétrica, pero a la derecha del plano general la pared se marca con luz no coloreada. La muestra obtenida, 247R 237G 246B, indica una corrección total de la temperatura de color. Tanto esta como la luz coloreada por las vidrieras quedan totalmente justificadas.

Los apliques del fondo están apagados, por lo que no marcan las paredes; y aunque los flexos de las mesas están encendidos, su luz no es demasiado reseñable puesto que el efecto de luz es día. Las medidas en la pared cercana a uno de los apliques, apagados, es lumínicamente del 23 \% y colorimétricamente de 59R 55G 45B.

\section{Análisis de la Escena 36. Redacción de la revista Sucesos, interior/noche}

Esta escena también transcurre en el decorado de la redacción de la revista Sucesos. La escena 36 es de nuevo interior, pero con efecto de luz noche. Cuenta con 28 planos 
y una duración de 1 minuto y 29 segundos. La diégesis se centra en Jesús, el redactor jefe, y la periodista Asunción, acompañados de la figuración de redactores.

La acción dramática de la escena se basa en una conversación entre Asunción y Jesús acerca de la redacción y corrección de los artículos de la periodista. Asunción aprovecha el momento para leer el artículo sobre el indulto. Le dice a su jefe que le gusta, y que ojalá lo concediesen. El redactor jefe también lo espera.

De la escena anterior donde anochece en Madrid —montada con imágenes en blanco y negro del NO-DO - se pasa a esta, técnicamente, por corte. Se inicia en blanco y negro, y se cambia a color cuando se cruza un figurante con un efecto realizado en posproducción. La realización sigue la técnica del plano-contraplano, con una cámara en plano general mientras que el resto, en angulaciones opuestas, proporciona el plano medio de cada personaje. Las tres cámaras están a la misma altura, aunque el redactor jefe está sentado y la periodista de pie, dada la escasa estatura de esta última. A la escena 37 se pasa por corte.

En el análisis global de la luz se puede afirmar que, de nuevo, la luz principal —que también actúa de contraluz - proviene de la fila de lámparas del fondo y se rellena con luz difusa. Pero como el efecto es noche, la cantidad de luz total de la escena es menor. Además, todos los apliques de escena están encendidos; y la luz que entra por las ventanas es menor y de un tono azulado. La escena presenta una tonalidad más anaranjada que la anterior, grabada con efecto de luz día. Está iluminada en clave baja, sin sombras excesivas, con luces difusas y corrección parcial de la colorimetría.

La justificación de la luz de la escena es total. La procedencia de la cantidad de luz está justifica por los apliques presentes en la escena. La luz principal proviene de la fila de lámparas del fondo, los apliques de pared marcan sobre ellas y el haz de los flexos incide sobre las mesas. La mezcla de luces está justificada por la presencia de las ventanas, por las que entra la luz azulada de la noche, y los apliques, de luz anaranjada.

El análisis individualizado toma la misma referencia de la escena anterior. Así, la luz principal proviene del fondo del decorado, $180^{\circ}$, situada a una altura de unos $60^{\circ}$. Su luminosidad, medida sobre las luces en la camisa del redactor jefe, es del $83 \%$ (similar a la de la escena anterior). De nuevo la proporcionan fuentes de luz difusa justificadas por las lámparas del fondo. En términos colorimétricos la medida, 212R 204G 195B, es similar a la de la escena anterior, sin dominantes apreciables.

No se precisa contraluz. La luz de relleno ilumina desde la posición de cámara, a $0^{\circ}$ en horizontal y vertical, y su luminosidad, medida sobre las sombras en la misma camisa, es del 40 \% (43\% menor que la principal), como en la escena interior/día. 
Es una luz difusa con una ligera corrección a dominante anaranjada, 101R 98G 82B, respecto al relleno utilizado anteriormente, 105 R 101 G 91 B.

Como se trata de una escena nocturna, todos los apliques de escena están encendidos y marcan las superficies sobre las que inciden sus haces. A diferencia de la escena diurna, ahora el símil de luz nocturna ilumina suavemente las vidrieras de las ventanas con una tonalidad azulada. Esta última luz está situada a $90^{\circ}$ a la derecha y a una altura de $50^{\circ}-60^{\circ}$. Su luminosidad, medida sobre las mismas altas luces que marcan la pared, es del 60 \% (en este caso, 23 \% inferior a la luminosidad de la luz principal, $83 \%$ ).

La luz del proyector que entra por la ventana queda justificada como simulación de luz nocturna. La proporciona un proyector de luz dura, ahora con su intensidad reducida un $37 \%$ respecto a la escena iluminada con efecto de luz día. También debe reseñarse la luz de fondos de los apliques de pared: su intensidad, medida sobre la pared que iluminan, es del $67 \%$ (44\% mayor que en la escena anterior, en la que están apagados). Prácticamente es idéntica a la intensidad de la luz que entra por la vidriera de la derecha.

En este caso, la corrección de la luz de fondos es parcial. La luz nocturna que entra por la ventana es azulada, 137R 136G 152B, y la de los apliques en imagen anaranjada, 171R 148G 110B. La mezcla de luces está justificada por la presencia en imagen de lámparas artificiales y las ventanas a la derecha del decorado por las que entra el símil de haz lunar.

\section{Análisis global de Amar en tiempos revueltos T.07 C.01}

El primer capítulo de la séptima temporada de la telenovela Amar en tiempos revueltos está iluminado en clave baja con fuentes difusas mediante la técnica de las medias luces retrasadas: la luz principal proviene del lado opuesto a la posición de las cámaras, $180^{\circ}$. Esta técnica no precisa del uso del contraluz, aunque sí de la luz de relleno; mientras que los fondos se tratan de manera independiente de los personajes.

La justificación de la cantidad de luz se busca en la presencia de ventanas o apliques de luz en escena. La corrección total de la colorimetría se da en las escenas diurnas, mientras que las nocturnas presentan corrección parcial, fundamentalmente en la luz de fondos. La mezcla de luces está justificada por la presencia de ventanas azuladas y luz artificial anaranjada.

Estos resultados pueden hacerse extensivos a toda la última temporada de Amar en tiempos revueltos (producida en alta definición, como se dijo). Así, puede considerarse que se utiliza un tratamiento de la iluminación a medio camino entre los programas de televisión habituales —iluminados permanentemente desde su inicio-y las ilu- 
minaciones de ficción más complejas — similares a las cinematográficas — en las que se crea un nuevo diseño de iluminación para cada escena, incluso para cada plano. El diseño de la iluminación en los decorados habituales, debido al ritmo industrial de trabajo, se realiza al comienzo de la producción. Aunque se suele ajustar al desarrollo de la acción, y cuenta con esquemas diferenciados para el día y la noche.

En los exteriores habituales, construidos en Cars Estudio, se dispone de proyectores permanentes y toldos de oscurecimiento para mantener el esquema de las medias luces retrasadas. Asimismo, en las localizaciones no habituales se intenta mantener este tratamiento lumínico.

En los interiores la diferenciación entre el día y la noche se consigue, fundamentalmente, con variaciones en los fondos. En las escenas interior/día, la luminosidad de la luz de fondos supera en más de un $10 \%$ a la de la luz principal y presenta una corrección total de la colorimetría; mientras que en las de naturaleza interior/noche su intensidad es cerca de $20 \%$ menor que la principal, y la corrección de la colorimetría es parcial. La intensidad de la luz de fondos varía entre el día y la noche, y la luz exterior desciende alrededor de un $30 \%$, mientras que la de los apliques asciende sobre un $40 \%$. Se consiente la mezcla de luces, anaranjada-azulada, de la luz artificial de los apliques frente al símil de luz natural nocturna que entra del supuesto exterior.

Este es un diseño adecuado de la iluminación de ficción que Alberto Ibáñez Brillas, jefe de la Unidad de Iluminación de Televisión Española, pone como ejemplo a sus alumnos en el Instituto de Radio Televisión Española.

Es una serie donde se saca un capítulo diario con una iluminación muy digna. Con poco tiempo y recursos, diaria, que graban muchos minutos útiles al cabo del día y hacen una iluminación muy decente donde diferencian muy bien los ambientes. Como he vivido lo complicado que es encontrarse en esa situación: muy digno (...) No, muy bueno. (Alberto Ibáñez Brillas, comunicación personal, 2009)

\section{Conclusiones}

Además del carácter inédito del enfoque del estudio, se proponen estrategias de creación propia para el análisis de contenido tales como la tipología que delimita la actuación cromática de los profesionales de la luz; la clasificación de los formatos seriados de ficción televisivos mediante condiciones excluyentes (a la búsqueda de la operatividad del modelo), o la toma de medidas cuantitativas para el estudio cualitativo de las cuatro luces.

Asimismo, la ficha elaborada se configura como un paradigma de análisis completo, pautado y estructurado, susceptible de convertirse en un modelo válido para el estudio de la iluminación de ficción televisiva, dado que los conceptos incluidos son lo 
suficientemente exhaustivos para extraer conclusiones y hacer predicciones. Además, dicha exhaustividad permite que pueda ser utilizada en el estudio de la iluminación de cualquier producto audiovisual.

\section{Referencias}

Amigo, B. (2005). Interpretación, cognición y teoría de géneros televisivos. En Documentos de trabajo del Centro de Estudios de la Comunicación. Instituto de la Comunicación e Imagen, 2, 38-65. Recuperado de https://taller5a.files.wordpress.com/2010/02/televisionygenero01.pdf

Aronovich, R. (2005). Exponer una historia. La fotografía cinematográfica. Gedisa.

Barroso, J. (2002). Realización de los géneros televisivos. Síntesis.

Bermingham, A. (2010). Iluminación de localizaciones para televisión. Instituto Radiotelevisión Española.

Carrasco, A. (2010). Teleseries: géneros y formatos. Ensayo de definiciones. Miguel Hernández Communication Journal, 1, 174-200.

Casetti, F. y Di Chio, F. (1999). Análisis de la televisión. Instrumentos, métodos y prácticas de investigación. Paidós.

Castillo, J. M. (2009). Realización, televisión y lenguaje audiovisual. Instituto Radiotelevisión Española. Cebrián, M. (1981). Diccionario de radio y televisión. Alhambra.

Cortés Lahera, J. Á. (2008). La programación de las series familiares. En M. Medina Laverón, Series de televisión. El caso de Médico de familia, Cuéntame cómo pasó y Los Serrano (pp. 75-100). Ediciones Internacionales Universitarias.

Chicharro, M. M. y Rueda, J. C. (2008). Televisión y ficción histórica: Amar en tiempos revueltos. Comunicación y sociedad, 21(2), 57-84.

Chion, M. (1992): El cine y sus oficios. Cátedra.

Diagonal TV (2005-2012). Amar en tiempos revueltos. TVE. Recuperado de http://www.diagonaltv. es/amar-en-tiempos-revueltos/

Diego, P. (2010). La ficción en la pequeña pantalla. Cincuenta años de series en España. Eunsa.

Diego, P., y Pardo, A. (2008). Estándares de producción de "dramedias" familiares en España: el caso de Médico de familia, Cuéntame cómo pasó y Los Serrano. En M. Medina Laverón, Series de televisión. El caso de Médico de familia, Cuéntame cómo pasó y Los Serrano (pp. 45 74). Eunsa.

Field, S. (2002). El libro del guion. Fundamentos de la escritura de guiones. Plot Ediciones.

García de Castro, M. (2002). La ficción televisiva popular: una evolución de las series de televisión en España. Gedisa.

Gordillo, I. (1999). Narrativa y televisión. Mad.

Jacoste Quesada, J. (1996). El productor cinematográfico. Síntesis.

Loiseleux, J. (2005). La luz en el cine. Cómo se ilumina con palabras. Cómo se escribe con la luz. Paidós. 
López-Pumarejo, T. (1987). Aproximación a la telenovela. Dallas/Dinasty/Falcon Crest.

Marzal Felici, J. (2004). Modelo de análisis de la imagen fotográfica. Grupo de investigación Itaca de la Universitat Jaume I. Recuperado de http://www.analisisfotografia.uji.es/

Migelez, X. (2013, enero 4). La sobremesa de TVE se encarece: de los 56.000 euros por capítulo de 'Amar...' a los 80.000 euros del nuevo serial. Formulatv.com. Recuperado de http://www. formulatv.com/noticias/28336/sobremesa-tve-se-encarece-56000-euros-capitulo-amar-entiempos-revueltos-80000-euros-nuevo-serial.

Millerson, G. (2008). Iluminación para televisión y cine. Instituto Oficial de Radiotelevisión Española.

Moreno, I. (2003). Narrativa audiovisual publicitaria. Paidós.

Navarro, P. y Díaz, C. (1994). Análisis de contenido. En J. M. Delgado y J. Gutiérrez (Eds.), Métodos y técnicas cualitativas de investigación en ciencias sociales (pp. 177-224). Síntesis.

Rincón, D., Justo, A., Latorre, A. y Sans, A. (1995). Técnicas de investigación en ciencias sociales. Dykinson.

Scheaffer, R., Mendenhall, W. III y Lyman, R. (2006). Elementos de muestreo. Paraninfo.

Sáinz, M. (2002). El productor audiovisual. Síntesis.

Saló, G. (2003). ¿Qué es eso del formato? Como nace y se desarrolla un programa de televisión. Gedisa.

Toledano, G., y Verde, N. (2007). Cómo crear una serie de televisión. TEB Editores.

TVE (2011). Amar en tiempos revueltos. T7. Capítulo 1. A la carta Televisión y Radio. Recuperado de http://www.rtve.es/alacarta/videos/amar-en-tiempos-revueltos/amar-tiempos-revueltos-t7capitulo-1/1189920/

Zeki, S. (2002). La imagen visual en la mente y el cerebro. Investigación y Ciencia, Temas 27, El Color, 70-79. 